Article

\title{
An openBIM Approach to IoT Integration with Incomplete As-Built Data
}

\author{
Nicola Moretti ${ }^{1, *} \mathbb{\infty}$, Xiang Xie ${ }^{1, *} \mathbb{C}$, Jorge Merino ${ }^{1}\left(\mathbb{D}\right.$, Justas Brazauskas ${ }^{2} \mathbb{C}$ \\ and Ajith Kumar Parlikad ${ }^{1}$ (D) \\ 1 Institute for Manufacturing, Department of Engineering, University of Cambridge, \\ 17 Charles Babbage Road, Cambridge CB3 0FS, UK; jm2210@cam.ac.uk (J.M.); aknp2@cam.ac.uk (A.K.P.) \\ 2 The Computer Laboratory, Department of Computer Science and Technology, University of Cambridge, \\ 15 JJ Thomson Ave, Cambridge CB3 0FD, UK; jb2328@cam.ac.uk \\ * Correspondence: nm737@cam.ac.uk (N.M.); xx809@cam.ac.uk (X.X.)
}

Received: 2 November 2020; Accepted: 19 November 2020; Published: 23 November 2020

Featured Application: The proposed methodology has been developed to support the Asset Management (AM) decision making according to an open Building Information Modelling (openBIM) approach. Within the context of the West Cambridge Digital Twin Research Facility, a real case scenario has been considered, where the as-built data is imprecise or absent. The methodology is well suited to dealing with incomplete data on existing buildings, when the objective is integration among AM, the Internet of Things (IoT) and BIM information.

\begin{abstract}
Digital Twins (DT) are powerful tools to support asset managers in the operation and maintenance of cognitive buildings. Building Information Models (BIM) are critical for Asset Management (AM), especially when used in conjunction with Internet of Things (IoT) and other asset data collected throughout a building's lifecycle. However, information contained within BIM models is usually outdated, inaccurate, and incomplete as a result of unclear geometric and semantic data modelling procedures during the building life cycle. The aim of this paper is to develop an openBIM methodology to support dynamic AM applications with limited as-built information availability. The workflow is based on the use of the IfcSharedFacilitiesElements schema for processing the geometric and semantic information of both existing and newly created Industry Foundation Classes (IFC) objects, supporting real-time data integration. The methodology is validated using the West Cambridge DT Research Facility data, demonstrating good potential in supporting an asset anomaly detection application. The proposed workflow increases the automation of the digital AM processes, thanks to the adoption of BIM-IoT integration tools and methods within the context of the development of a building DT.
\end{abstract}

Keywords: BIM; openBIM; IFC; IoT; sensors; cognitive buildings; asset management; digital twin

\section{Introduction}

Asset Management (AM) is a key organisational area in Architecture, Engineering, Constructions and Operations (AECO), being a recognised and effective driver for better sustainability of the built environment, while improving asset condition and performance [1,2]. Moreover, the management of the built environment has entered a new phase characterised by a digital transformation of management processes [3]. This phase concerns the adoption of digital tools that can support the production, storage and update of information during the life cycle of assets [4-6]. 


\subsection{Digital Modelling in Asset Management}

Building Information Modelling (BIM) is now widely adopted by the industry as part of their digital toolkit, especially when focusing on building systems and components. BIM for building operation has been standardised internationally by ISO 19650-3 [6], which provides guidance for information management during the use phase of the assets [7]. The benefits of BIM have been studied in multiple domains, for example, maintenance prioritisation [8,9], energy management [10], sustainability assessment [11] and life cycle costing [12]. Advances in BIM are likely to reduce the time needed to update databases in the use phase by $98 \%$ [13]. However, as a dynamic system, one of the most relevant contemporary challenges in AM concerns the integration of the static data stored and managed through Asset Management Systems (AMS), with the dynamic data provided by Building Management Systems (BMS) [14] and Internet of Things (IoT) sensor networks deployed for specific building management applications [15]. The concept of Digital Twins (DT) aims to address the integration of static and dynamic data, thereby enabling the creation of a digital replica of the physical building that is always up-to-date through its life cycle [16]. DTs are therefore integrated, multifaceted, and multi-scale digital replicas of physical assets, systems, processes, and buildings, that accelerate the development and benefits of BIM in AECO [17,18].

\subsection{Data Integration Management}

AM processes are still managed based on outdated procedures in practice, hindering the innovation and adoption of digital technologies that could strongly support information management and contribute to the integrity, validity and interoperability of the process [19]. DTs for built environments are still in their infancy, and there are few applications that integrate static and dynamic data in AECO, which is a laggard economic sector in terms of adopting innovative digital tools [20].

The following issues were identified regarding the lack of integration between static and dynamic information in AM:

- BIM models are often created during the design, manufacturing, and construction phases using unclear procedures, and updated as-built models are hardly accessible or even not available. In addition to the static nature of BIM, outdated and unreliable (i.e., inaccurate and incomplete) building information impedes the full potential of the AM applications during the use phase.

- Even when updated as-built BIM data is available, scarce attention is still paid during the design phase to the information management process across the whole asset life cycle. Consequently, the information requirements (IRs) during the use phase are often not met because of the way information is created and aggregated (e.g., classified), during the design and construction phase. BIM is a flexible modelling approach, which supports the inclusion of geometries, assets and systems as part of the model. However this flexibility may result in chaos if recognisable hierarchies and classification systems are not defined in the design phase and adopted during the assets' life cycle.

- Static and real-time data are managed differently because of their nature. For instance, some asset information is designed to be static (e.g., asset locations and geometries), whereas asset performance is measured in real-time in DTs throughout the use phase. Static data is not updated frequently (or at all) and is stored in passive repositories (e.g., relational data-bases or files to query or in COBie spreadsheets). Real-time data is variable, requiring special storage and management (e.g., actively publishing new data for active subscribers). IRs are clearly different for static and real-time data, leading to AM applications that cannot use both sources of information.

To the three main issues described above, a fourth can be added, concerning the inaccessibility of proprietary data formats: siloed black box systems that vendors use often make data interoperability impossible.

Efforts have been made to enable more flexible data integration for AM. On one hand, several studies are currently being conducted to improve the information exchange during the life 
cycle of the assets within the openBIM approach [21]. OpenBIM indicates the use of BIM based on open standards and workflows to improve the openness, reliability and sustainability of life-long data and enable flexible collaboration between all stakeholders. An example is ongoing standardisation efforts by the International Organisation for Standardisation (ISO), on the 19650 series of standards [4-6]. On the other hand, quality AM processes are being investigated using incomplete and inaccurate information, particularly on existing assets.

\subsection{Aim of the Paper}

The aim of this paper is to present an openBIM methodology to overcome the separation of existing static/dynamic information in supporting AM applications with awareness of inaccurate and incomplete as-built data. The benefits of this approach include:

- Improved accessibility of the integrated information;

- Users' profiling and access to the right data at the right moment;

- Dynamic AM application support, with limited as-built information availability and

- Enhanced information quality by better matching with the domain specific requirements from different AM applications.

\section{State of the Art}

The BIM approach can be broadly defined as a set of digital modelling tools, procedures, and methods that support the effective management of information flows during the life cycle of the asset [22]. The benefits of BIM adoption in AM and Facility Management (FM) are well documented $[19,23,24]$ :

- It improves the quality of building data (e.g., preventing data replication and limiting redundancy and inconsistency);

- It facilitates data integration during the building life cycle;

- It improves communication between stakeholders;

- It enables smoother workflows among involved parties according to standardised procedures;

- It allows a reduction in time and cost in the retrieval of FM related information;

- It enables a faster verification process.

Improved information management (i.e., integration, quality, sharing) is the primary benefit that can be achieved through implementing BIM approaches. Through the incorporation of geometry, spatial locations and semantic properties, BIM provides a high-fidelity representation for buildings. The buildings' interaction with users is captured by IoT sensors which are increasingly deployed in the built environment to collect real-time data on the operational condition of buildings [15]. The integration of BIM and IoT has been identified as the key driver for the realisation of cognitive buildings, smart infrastructure and, eventually, the smart built environment $[25,26]$. Several applications of BIM and IoT data integration can be found in the literature.

\subsection{Uses of the BIM and IoT Technologies}

In the manufacturing and construction phase, sensor data and BIM technologies can be used to monitor the construction site schedule and improve the procurement process [27]. The use of Virtual and Augmented Reality (VR/AR), which simulate the reality using either virtual reality headsets or multi-projected environments or simply add digital elements to a live view (e.g., the game Pokemon Go), can support construction operations and prevent issues in the execution process (e.g., interference among systems and structural parts) [28]. Global Positioning System (GPS) technologies and Radio-Frequency IDentification (RFID) sensors are utilised to monitor the positioning of building components against the BIM model [29]. In construction logistics and management, IoT data can be employed to track and improve construction site operations [29] within the context of 
the lean construction, concerning the digitisation and automation of the construction supply chain [30]. In Health and Safety (H\&S) management, VR and BIM data have been employed to improve the training process of workers, and their ability to recognise and assess risks [31]. In the same sector, Ref. [32] propose integrating wireless sensor networks and BIM technologies to monitor the safety status (presence of hazardous gas) of underground constructions sites.

In FM, BIM and IoT data integration have been studied to enrich the condition monitoring of critical assets and real-time assessment of their performance [33]. VR/AR technologies enhance indoor navigation [34], which upgrades maintenance procedures. BIM and energy data integration improves energy management [35]. Ultrasonic sensors can be used with BIM for maintenance service optimisation [36]. Dynamic environmental data can be used to achieve higher user comfort and to adapt system behaviour [37].

The number of applications is growing, and the topic has gained momentum, representing a leading research field, which lays a solid foundation for the identification, collation and curation of operational datasets and demonstrating the great potential of the DT applications in AECO.

\subsection{Integration Architectures}

Besides the applications that can be developed through fruitful BIM and IoT integration, a critical aspect can be found in the static and dynamic data integration. The development of an effective architecture allows for leveraging of the true potential of static information concerning geometries, location and relations among the building elements and the related semantics stored in the BIM model; AM and FM information is generally collected in an Asset Information Model (AIM) [8]; and the dynamic data streamed through the IoT technologies and managed through the related infrastructures. Different types of architecture can be found in the literature, allowing diverse operations on data. Ref. [15] classifies these architectures according to five methods, as shown in Table 1. These methods fulfil the integration of BIM and IoT by utilising BIM tools' APIs and relational database, transform BIM data into a relational database using new data schema, create new query language, using semantic web technologies and hybrid approach, respectively. Basically, these methods keep contextual information (BIM data) and time-series (sensor collected) data, and integrate them from different angles. Their methodological description, advantages and disadvantages are explained in Table 1.

Table 1. BIM IoT data integration methods [15].

\begin{tabular}{|c|c|c|}
\hline Method & Advantages & Drawbacks \\
\hline $\begin{array}{l}\text { BIM tools' APIs + relational } \\
\text { database: Sensor and BIM data are } \\
\text { stored in a relational DB. Virtual } \\
\text { objects are connected to sensor data } \\
\text { through unique identifiers }[38,39] \text {. }\end{array}$ & $\begin{array}{l}\text { - } \quad \text { Extensive software support; } \\
\text { existing of APIs allow the } \\
\text { export/import of BIM data } \\
\text { in the right format; } \\
\text { - } \quad \text { easy of using SQL. }\end{array}$ & $\begin{array}{l}\text { - Poor in BIM data export and } \\
\text { enrichment capabilities; } \\
\text { insufficient of model change } \\
\text { management support. }\end{array}$ \\
\hline $\begin{array}{l}\text { New data schema creation: } \\
\text { Transform BIM data into relational } \\
\text { database using new data } \\
\text { schema }[40,41] .\end{array}$ & $\begin{array}{ll}\text { - } & \text { Flexible in users' } \\
\text { customisation; } \\
\text { - } & \text { supporting data federation } \\
\text { (no need for conversion); } \\
\text { - allow effective data } \\
\text { management in large } \\
\text { projects. }\end{array}$ & $\begin{array}{l}\text { Time-consuming in mapping } \\
\text { operations; } \\
\text { requires BIM data knowledge } \\
\text { and editing skills. }\end{array}$ \\
\hline $\begin{array}{l}\text { Create a new Query Language } \\
\text { (QL): for querying time-series and } \\
\text { IFC data }[42,43] \text {. }\end{array}$ & $\begin{array}{ll}- & \text { Expressiveness of QL; } \\
\text { - } & \text { optimised for } \\
& \text { domain-specific } \\
& \text { applications. }\end{array}$ & $\begin{array}{ll}\text { - } & \text { Scarce dynamic data query } \\
\text { capabilities; } \\
\text { - } \quad \text { need to develop a dedicated platform; } \\
\text { - no standardisation. }\end{array}$ \\
\hline
\end{tabular}


Table 1. Cont.

\begin{tabular}{|c|c|c|}
\hline Method & Advantages & Drawbacks \\
\hline $\begin{array}{l}\text { Semantic web approach: } \\
\text { for storing, sharing, using } \\
\text { heterogeneous data }[44,45] \text {. }\end{array}$ & $\begin{array}{l}\text { - } \quad \text { Linking data silos; } \\
\text { managing cross-domain } \\
\text { information; } \\
\text { - } \\
\text { bffective in projects with } \\
\text { broad scope. }\end{array}$ & $\begin{array}{l}\text { - } \quad \text { Need to represent data in } \\
\text { - } \quad \text { RDF is not optimal for querying } \\
\text { dynamic data; } \\
\text { - } \quad \text { data redundancy risk; } \\
\text { - fix structure and storage consuming. }\end{array}$ \\
\hline $\begin{array}{l}\text { Hybrid approach: semantic web + } \\
\text { relational database: both } \\
\text { approaches are used for storing } \\
\text { cross-domain data }[46,47] .\end{array}$ & $\begin{array}{l}\text { - } \quad \text { Data is stored in the most } \\
\text { - } \quad \text { time saving (no conversion); } \\
\text { - } \quad \text { storage saving; } \\
\text { - } \quad \text { better performance; } \\
\text { - } \quad \text { effective QL. }\end{array}$ & - $\quad$ RDF conversion still needed. \\
\hline
\end{tabular}

\section{The Proposed Openbim Methodology}

In this section the methods employed to develop the proposed openBIM approach for IoT data integration are presented while exposing the limitations. Then, the proposed workflow is depicted addressing these limitations to leverage the full potential of the available static and dynamic data, supporting the development of AM applications, even when as-built data is incomplete. The purpose is to create an approach that is effective when dealing with existing buildings where as-built information is frequently absent or not reliable.

The proposed openBIM approach aims to extend the BIM methods and tools for improved accessibility, usability, management and sustainability of data in AECO [21]. It promotes data sharing and collaboration among parties using open standards, addressing the common BIM issues related to proprietary technologies and software. For this purpose, the Industry Foundation Classes (IFC) data schema has been adopted to support and handle the BIM data [48].

The IFC schema is an object-oriented open standard [49] widely studied as an effective means for interoperability, sharing, collaboration and classification. The IFC schema is extensive and complex, and therefore its usage has been limited to simple software interoperability workflows and visualisation of key information of the BIM model. Nonetheless, IFC offers good support for not only geometry representation, but also semantic data enrichment. In this research, the If cSharedFacilitiesElements schema has been employed to handle geometric and semantic information of both existing and newly created IFC objects, supporting real-time data integration.

Rarely, the level of both geometric and semantic detail and the classification system (the granularity) adopted in developing the BIM model, in the design and construction phase, is adopted in the use phase. According to [50], the IfcAsset has been adopted for re-aggregating building components in order to achieve the desired level of granularity used in AM. The IfcAsset (the element breakdown is elaborated in Figure 1) is defined as "a grouping of elements acting as a single element that has a financial value", allowing objects that are not spatially connected to be related, through the relationship IfcRelAssignsToGroup. Moreover, another artefact that can be leveraged for semantic enrichment of the BIM model is the IfcAsset, which allows the objectified relationships IfcAssignToActor, IfcAssignToControl, IfcAssignToProcess and IfcAssignToResources to be associated with a wide set of data within the context of the AM domain.

In practice, as-built data is incomplete and not reliable. When integrating with IoT data, this may result in hampering an effective digital representation of both the sensor objects and the spatial elements measured by the sensors. This issue is addressed by modelling non-geometric objects in IFC, which allows a modular updating of the BIM model. This approach leverages both the 3D and semantic potential of the IFC schema, streamlining the integration of BIM, AM and IoT data.

From the perspective of applications, detailed spatial/geometrical information is not always necessary. As typical distributed systems, buildings need to be monitored, managed and controlled. 
Eventually, buildings' performance can be simulated under known building systems organisation using individual asset components. For instance, for the anomaly diagnosis of Heating, Ventilation and Air-Conditioning (HVAC) systems in a specific building, only the basic mechanical system information is needed: describing the HVAC system configuration and the links between architecture zones and HVAC terminal units [51]. This scenario is used in Section 4 for demonstrating the benefits of the proposed approach. In the development of the IfcAsset, in fact, the classification system adopted by asset and facility managers must be considered in order to support inter-operable and flexible AM processes. For querying and modifying the IFC, several Application Programming Interfaces (APIs) can be used. The IfcOpenShell-python (http:/ /ifcopenshell.org/) module and the BIMserver (https:/ / github.com/opensourceBIM/BIMserver) software for IFC visualisation and queries are used in this research.

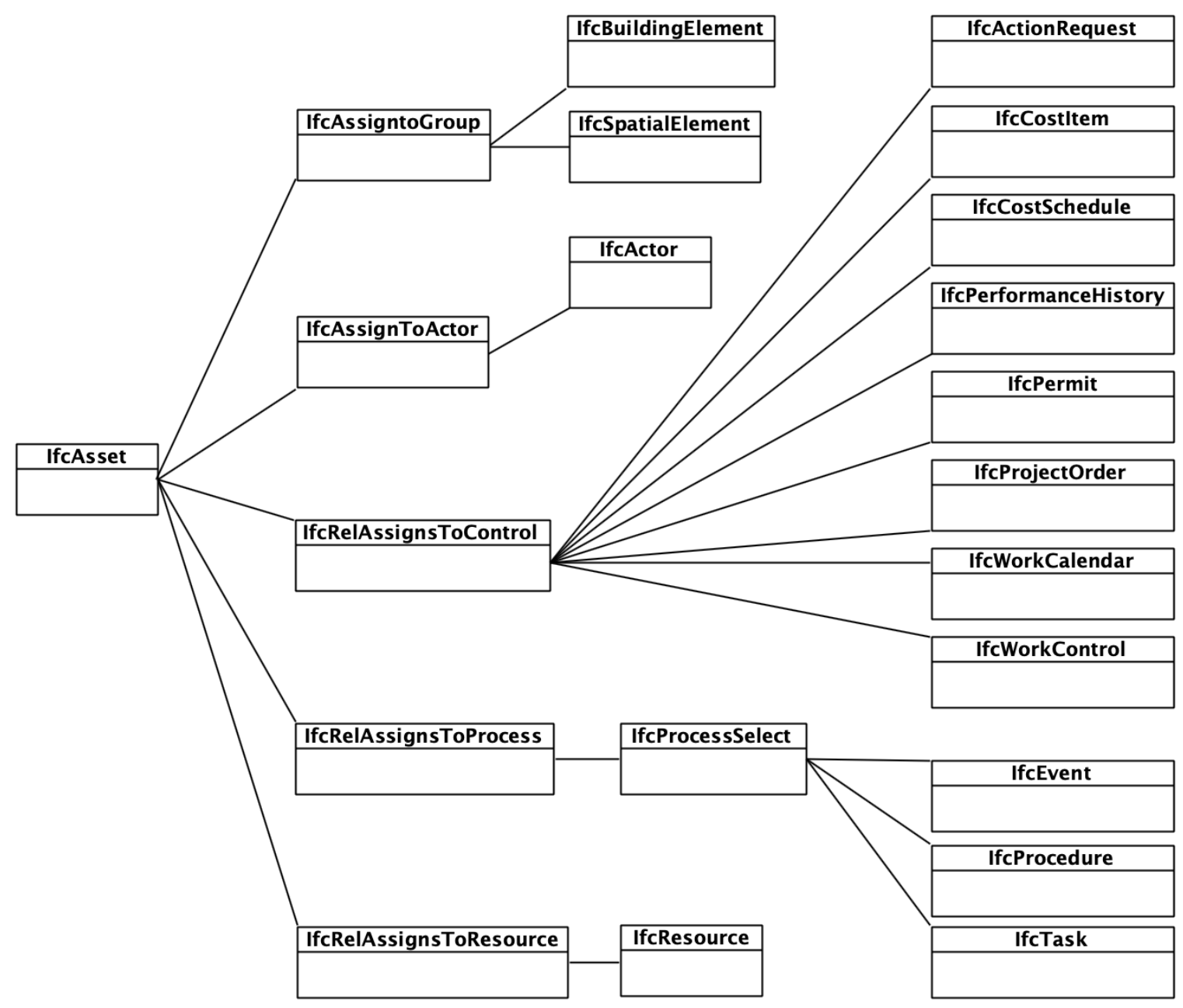

Figure 1. IfcAsset schema.

Figure 2 depicts the proposed methodology. The process starts with the definition of IRs, which is designed to identify the relevant data employed for the operation of the building according to the business and client needs and the outcomes of the application. This step is composed of three sub-tasks regarding the definition of the static and dynamic IRs and the definition of the Service Level Agreements (SLAs).The static IRs correspond to the AM information, characterised by a low frequency of updates and more classical information management. Static IRs include the level of aggregation of the assets (granularity) at which the maintenance interventions are conducted. The dynamic IRs concern the IoT data management, including how to aggregate data into indicators to measure performance through the installed sensors, and how to associate this information with the physical 
and spatial elements of the building. The SLAs concern the performance agreed for operating the assets at an acceptable service level.

The IRs definition step is crucial to the IFC processing and the creation of the IfcAsset assignment relationships. The IFC processing should consider the classification system used for AM (explicitly related to how the static and dynamic data are handled). This would facilitate the adoption of the methodology in practice and increase its usability.

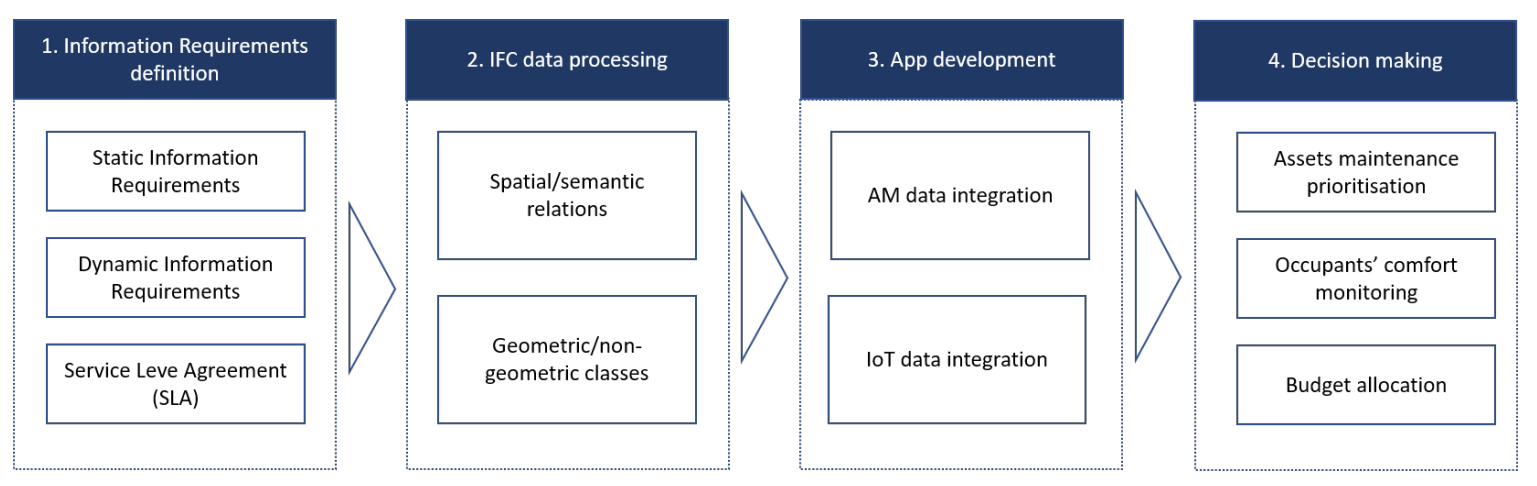

Figure 2. Research schema.

The next step is IFC data processing to meet the IRs. To achieve this, it is necessary to edit the initial IFC file generated through the BIM authoring software. IoT integration requires access to data schemes related to objects that might not be available (modelled) in the IFC file. This is a common issue with existing buildings, where the BIM information is partial or outdated as a result of the modifications of the physical elements and functions of the building during its use. These modifications can be recorded, for example, in the building logbook, but they are rarely collected and managed in BIM models. Furthermore, system components are frequently difficult to access and inspect, and therefore to model correctly in the BIM environment. For this reason, in a streamlined approach to BIM data updates, the geometry of not accessible (or visible) components may be overlooked, focusing mainly on the semantic enrichment. Nonetheless, the modular development of the digital model should always be considered, enabling detailed 3D data integration once available (e.g., through a detailed inspection, after a refurbishment). Additionally, to represent correctly the semantic relationships among the newly created and existing IFC classes, the objectified relationships also need to be modelled. This allows for the connection and effective querying of systematically interdependent IFC classes that are not originally related in the IoT applications. When dealing with existing building data, the aggregation and classification system adopted in design and construction does not match its counterpart used in operations. As a consequence, re-aggregation must be conducted to unlock the real potential of BIM data in AM. The IfcAsset class has been employed for this purpose as the grouping entity enabling the collection of homogeneous sets of elements forming the parts of the systems in the building.

The last step concerns IoT data integration. The entire IFC schema is not necessary to handle IFC and IoT integration; rather, it can be achieved by linking the sensor readings to the existing or newly created IFC classes, through the Globally Unique Identifier (GUID) of each IFC object. Therefore, only the relevant IFC subset need to be exported, following a Model View Definition (MVD) approach [52]. The MVD is essentially a filtered view of the IFC, which allows the extraction of specific packages of model information to meet a particular use. The application development and implementation based on this integration must support dynamic decision-making. Some of them are listed in the Step 4 in Figure 2. Step 2, IFC data processing will be discussed in detail in the following section.

\section{Case Study}

The proposed methodology has been applied to the Institute for Manufacturing (IfM) building located in the West Cambridge campus of the University of Cambridge. It is part of the West 
Cambridge DT Research Facility [18] and has been equipped with a customised IoT sensor network, comprising a set of Monnit (https:/ / www.monnit.com/Products/Sensor/) wireless sensors measuring indoor environmental and asset parameters, for instance, temperature $\left({ }^{\circ} \mathrm{C}\right)$, relative humidity $(\%)$, $\mathrm{CO}_{2}$ concentration (ppm) of indoor spaces and window open/close status, and HVAC pump vibration frequency $(\mathrm{Hz})$ among others.

A BMS, based on the Trend (http://www.trendcontrols.com/en-GB/) platform, is currently used to monitor the performances of mechanical, electrical and pumping (MEP) systems. This data remains in a different system and is not integrated with the IoT sensor data. Thus, it cannot easily be used together to make informed decisions on assets operations. To demonstrate the capability of the designed scheme, a typical anomaly detection application for the HVAC system monitoring is implemented [35].

Assets responsible for delivering the functionalities of the building determine the quality of the services and the comfort of the spaces that it provides for its inhabitants. Monitoring the working condition of the assets and further revealing the raised anomalies, either environmental or asset-wise, is important for guaranteeing building operational performance. As a result of the limitation in computational resources for buildings, the performances of HVAC system components are monitored individually without considering their interdependence. Even for individual component, the monitoring of assets anomaly detection, for operation and maintenance management requires comprehensive data sources, both static and dynamic, for re-classifying building facilities information. For the definition of the static information requirements, the following information has been considered:

- Geometries and location of the HVAC components, including primary air loop, variable refrigerant flow (VRF), water circulation pumps and radiators;

- Relevant data in the civil components of the building (technical specifications, active contracts, maintenance records, models and producer of the components);

- Sensor location and technical specifications;

- System architecture, that is, the way the HVAC system is organised from multiple components, according to a classification system;

- Interface requirements with the real-time platform.

The real-time information requirements are defined considering the following:

- Set points for the HVAC system (e.g., the temperature of the rooms, relative humidity, $\mathrm{CO}_{2}$ concentration);

- Data on comfort parameters measurements (BMS, Monnit sensors);

- Data on the BMS and IoT sensors status.

Table 2 collects the information requirements defined for two rooms (labelled G.44 and 1.58) and the related assets in the building. According to the anomaly detection application needs, the level of aggregation of the assets has been defined. This new bespoke classification has been employed to group the relevant building elements to be monitored through the anomaly detection application. Some were already present in the initial version of the IFC file (i.e., Table 2 marked as Existing "yes"), while others had to be created (as non-geometrical classes). In the modelling procedure, the IFC2x3 TC1 [53] version has been used. This version, despite being improved by Version 4 , offers wider software support, allowing more accurate visualisation of complex geometries, especially in commercial software. However, the possibility to upgrade the workflow with more recent IFC versions has been considered. 
Table 2. Anomaly detection application information requirements definition.

\begin{tabular}{|c|c|c|c|c|c|c|c|}
\hline Code & Asset & Sensor Name & Location & Sensor Type & Unit & IFC Entities & Existing \\
\hline G44 & G.44 (lev.0) & & & & & IfcSpace & yes \\
\hline G44_1 & & Monnit sensor & G.44 room & sensor unit & ${ }^{\circ} \mathrm{C} / \%$ & IfcSensorType & no \\
\hline G44_2 & & Temperature VRF & Air terminal at VRF 36 & sensor unit & ${ }^{\circ} \mathrm{C}$ & IfcEnergyConversionDevice & yes \\
\hline G44_3 & & Temperature VRF & Air terminal at VRF 37 & sensor unit & ${ }^{\circ} \mathrm{C}$ & IfcEnergyConversionDevice & yes \\
\hline G44_4 & & Fan speed VRF & Air terminal at VRF 36 & integrated & level (1-n) & IfcFanType & no \\
\hline G44_5 & & Fan speed VRF & Air terminal at VRF 37 & integrated & level (1-n) & IfcFanType & no \\
\hline $\mathrm{AHU}$ & AHU2 & & & & & IfcAsset & no \\
\hline AHU_1 & & AHU extract air temperature & after the air mixer & sensor unit & ${ }^{\circ} \mathrm{C}$ & IfcSensorType & no \\
\hline AHU_2 & & AHU extract fan speed & AHU extract fan & integrated & ls- $1 / \%$ & IfcFanType & no \\
\hline AHU_3 & & AHU extract air filter DPS & AHU extract air filter & integrated & $\mathrm{Pa}$ & IfcFilterType & no \\
\hline AHU_4 & & AHU supply air filter DPS & AHU supply air filter & integrated & $\mathrm{Pa}$ & IfcFilterType & no \\
\hline AHU_5 & & AHU supply fan speed & AHU supply fan & integrated & $1 \mathrm{~s}-1 / \%$ & IfcFanType & no \\
\hline AHU_6 & & AHU supply air reheat level & AHU supply air reheat & integrated & $\%$ & IfcCoilType & no \\
\hline AHU_7 & & AHU supply air temperature & before the air splitter & sensor unit & ${ }^{\circ} \mathrm{C} / \mathrm{Pa}$ & IfcSensorType & no \\
\hline AHU_9 & & Thermowheel exchange rate & Thermowheel & integrated & $\%$ heat & IfcAirToAirHeatRecoveryType & no \\
\hline WR2 & WR2 & & & & & IfcAsset & no \\
\hline WR2_1 & & WR2 supply temperature & before WR2 loop & sensor unit & ${ }^{\circ} \mathrm{C}$ & IfcSensorType & no \\
\hline WR2_2 & & WR2 cooling pump DPS & WR2 cooling pump & integrated & $\mathrm{Pa}$ & IfcPumpType & no \\
\hline WR2_3 & & WR2 return temp & leaving WR2 loop & sensor unit & ${ }^{\circ} \mathrm{C}$ & IfcSensorType & no \\
\hline DAC_1 & & Dry air cooler DPS & DAC & integrated & $\mathrm{Pa}$ & IfcChillerType & no \\
\hline DAC_2 & & DAC on temp & before DAC & integrated & ${ }^{\circ} \mathrm{C}$ & IfcSensorType & no \\
\hline DAC_3 & & DAC off temp & after DAC & integrated & ${ }^{\circ} \mathrm{C}$ & IfcSensorType & no \\
\hline DIAL & 1.58 (lev. 1) & & & & & IfcSpace & yes \\
\hline DIAL_1 & & Space temp & space & sensor unit & ${ }^{\circ} \mathrm{C}$ & IfcSensorType & no \\
\hline RAD & Radiators & & & & & IfcAsset & no \\
\hline RAD_1 & & Radiator pump DPS & Radiator pump & integrated & $\mathrm{Pa}$ & IfcPumpType & no \\
\hline RAD_2 & & VT flow supply temp & radiator inlet & sensor unit & ${ }^{\circ} \mathrm{C}$ & IfcSensorType & no \\
\hline RAD_3 & & VT flow return temp & radiator outlet & sensor unit & ${ }^{\circ} \mathrm{C}$ & IfcSensorType & no \\
\hline RAD_4 & & VT heat meter & & sensor unit & Kwh & IfcFlowMeterType & no \\
\hline
\end{tabular}


In the definition of the IRs, IoT and BMS sensors are crucial for collecting data on the comfort and function of the spaces and equipment in the building. Different types of sensor had to be handled accordingly: environmental sensors (i.e., temperature, $\mathrm{RH}$ and $\mathrm{CO}_{2}$ ) have been related directly to the IfcSpace, while integrated sensors have been associated with the directly related building components (e.g., AHU_4.AHU supply air filter DPS in Table 2 have been associated to If cFilterType). After creating the missing IFC objects, they have been aggregated to form assets, through the IfcAsset. Figure 3 represents the updated IFC including missing building components in Table 2.
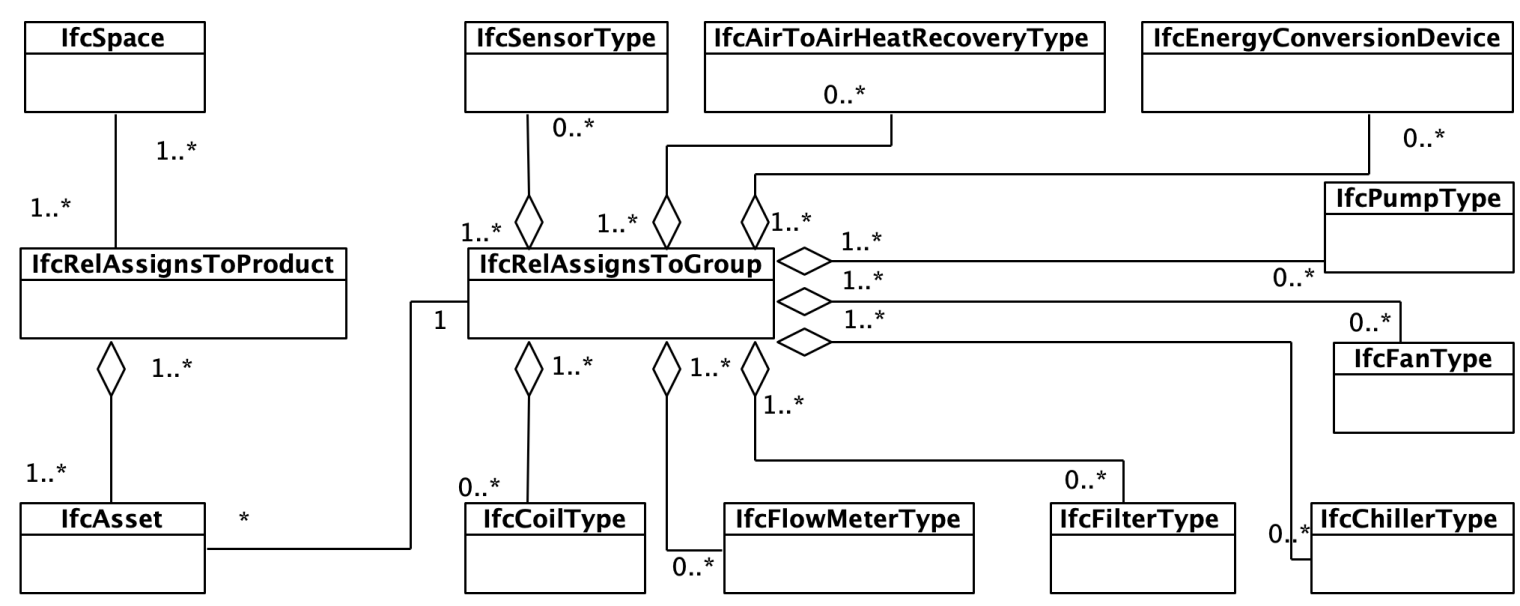

Figure 3. UML schema of the proposed approach implemented in the case study.

The entities necessary to develop the IfcAsset classes can be defined in advance through the IfcOpenShell-python software and are used as follows:

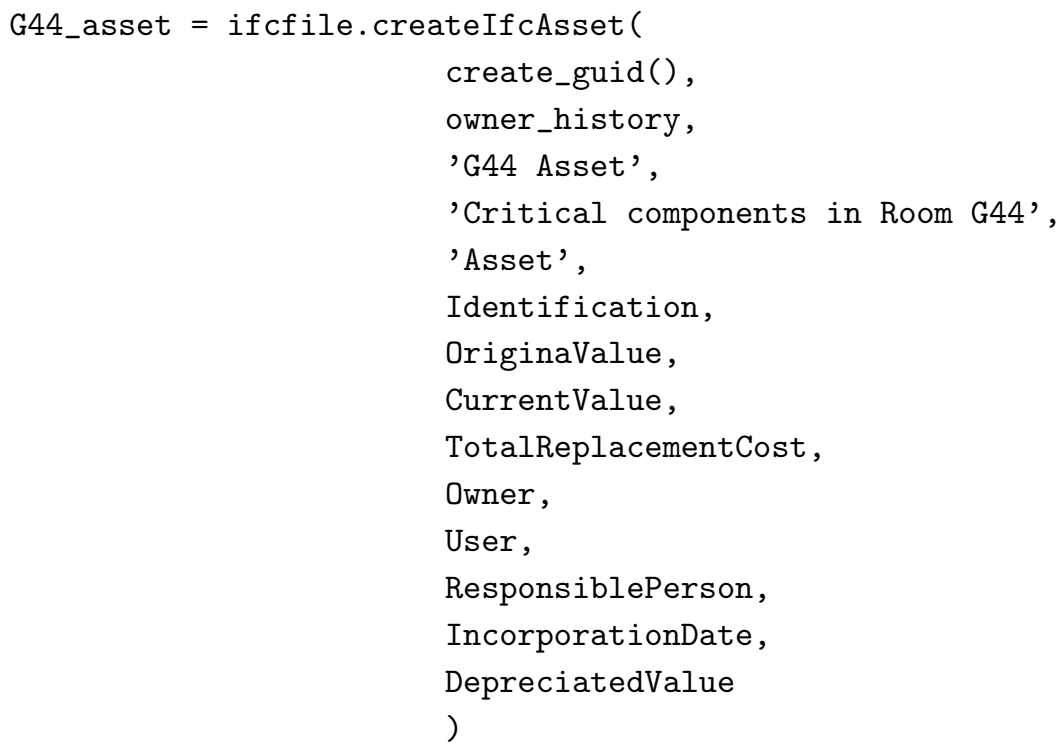

The relationships among the relevant elements and the assets are created and associated with the asset.

ifcfile.createIfcRelAssignsToGroup(

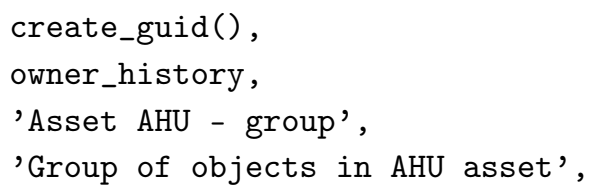


(AHU_1, AHU_2, AHU_3, AHU_4, AHU_5, AHU_6, AHU_7, AHU_9),

None,

AHU

)

Finally, the assets are connected to the served room.

ifcfile.createIfcRelAssignsToProduct(

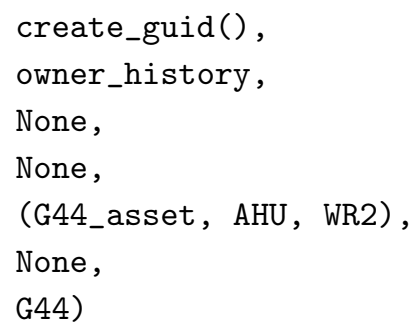

The processed IFC can be visualised and queried in BIMserver as displayed in Figure 4. Furthermore, the model can be queried through JavaScript Object Notation (JSON) queries, and the subset of the original IFC data can be downloaded, allowing the creation of MVDs able to support further data integration. This is relevant in the anomaly detection application since, after running necessary algorithms on dynamic data, it is possible to access the information related to the assets potentially responsible for the detected anomalies.

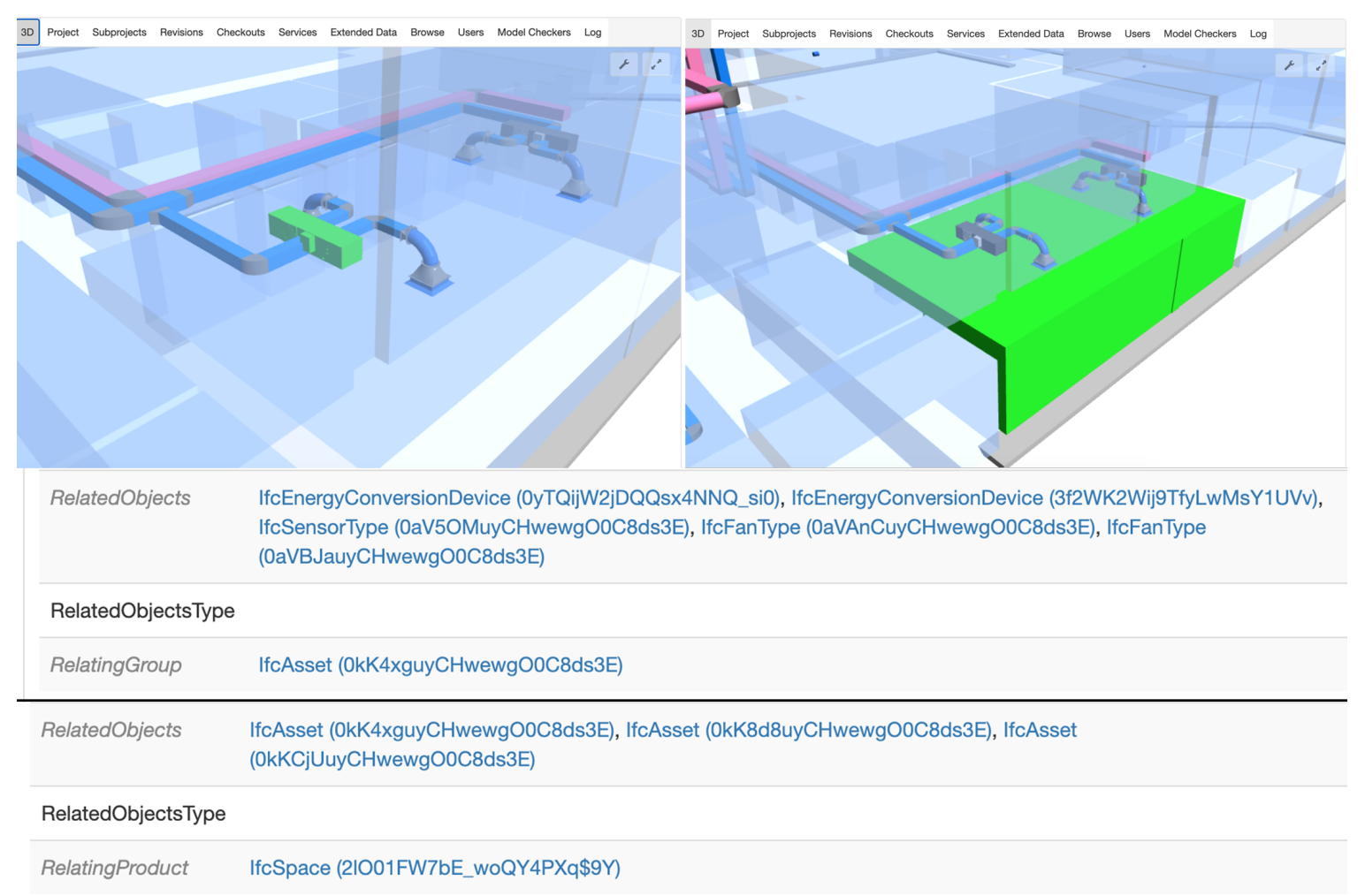

Figure 4. Visualisation of processed IFC through BIMserver.

Taking the asset anomaly detection application on the HVAC system as an example (Figure 5), the processed IFC lays a solid foundation for flexible data integration that supports corresponding AM functions. In this case, the real-time operational data of the HVAC components, such as the WR2 cooling pump and AHU extract fan, and the real-time environmental data of the regulated spaces, are integrated for analysis through the proposed approach (Figure 5). 


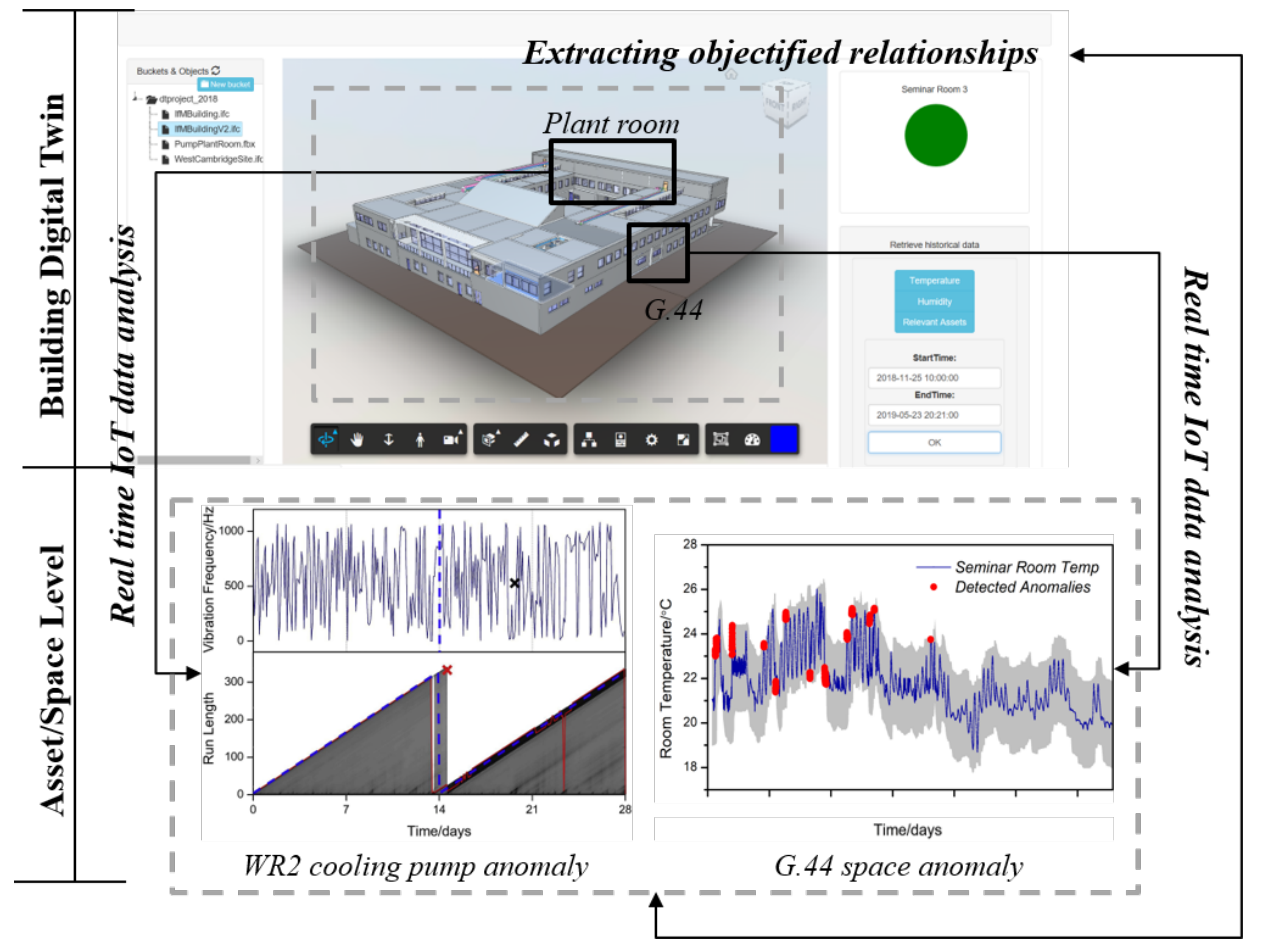

Figure 5. Anomaly detection application.

Contextual anomaly detection algorithms, like cumulative sum (CUSUM) control chart or Bayesian Online Change Point Detection (BOCPD), can be used to dynamically reveal anomalous behaviours that deviate from the anticipation [35]. Subsequently, extracting the objectified relationships among modelled assets and spaces, the causality of found anomalies can be inferred, and the root cause can be identified accordingly. Picking up the correlations of the unexpected anomalies, corresponding local repair, replacement and maintenance operation activities can be triggered to enable preventive maintenance and mitigate the effects of failure risk. In particular, the proposed approach provides a useful tool to back up semantic and geometric data management for AM applications and to facilitate the development of potential application areas [54].

\section{Discussion}

The proposed approach supports data integration and interoperability in the digital built environment. The methodology enables the effective utilisation of BIM data in the use phase of the assets, supporting the dynamic decision making. Data from the three systems (BIM environment, IoT platform and BMS) were integrated and processed, focusing on the usability of the systems, building a new data structure on top of the existing data sets. Accordingly, information can be accessed and used, integrating and supporting the workflows and operations of the asset management team. The data re-aggregation and processing allows useful insights supporting operations in AM of cognitive buildings'.

The methodology was developed employing open source software for better interoperability and cross-platform usage. In addition, the open standard IFC is used to support information management in the context of the cognitive buildings and smart built environments. IFC also allows the accessibility and integration capabilities to be increased in the development of further applications. The proposed approach, considering the Digital Twin system architecture proposed by [18], sits in the Data/Model integration layer and therefore supports the data integration for the development of multiple AM applications.

IFC artefacts such as IfcAsset and IfcSharedFacilitiesElements were used in the proposed methodology to enable data integration, including the association with the controls and processes 
(Figure 1) capable of supporting the automation of AM processes. Although the enrichment of the IFC schema with relevant AM information (e.g., contractors, resources, economic and financial data, maintenance planning data etc.) may be beneficial in the standardisation of the data collection and process, it can also result in storage and update issues. IFC is a static data format, which poorly supports the dynamic data update. Accordingly, the IRs definition phase in this methodology is vital to the success of this approach, since it includes the potential uses of data during operation.

The case study demonstration was conducted using IFC $2 \times 3$, despite Version 4 [48] being available. The methodology can be adapted to the newest version for the data set based on Version 4 . The application of the workflow to a digital model with more detailed geometries is possible, since the type entities have been generated in IFC for non-geometric virtual elements. The types can be related to the geometric objects by means of the IfcRelDefinesByType relationships, once they become available (e.g., after a refurbishment). After updating the IFC with geometries, further capabilities of the schema can be leveraged for location-enabled AM services (e.g., indoor navigation, H\&S and agent-based simulations).

Despite IFC being one of the primary means for interoperability and openBIM standards, it often needs to be converted to be fully usable in the development of software applications. A conversion procedure should be defined. BIMserver offers the possibility to export a sub-set of the imported IFC data, in order to achieve this result. Data can also be exported in JSON format, enabling the development of more generic and cross-domain applications [55]. This process should follow the MVD approach [52] in order to be repeatable and recognisable within the BIM domain, even though this approach is not extensively described in this article. Accordingly, it is possible to enhance the capabilities offered by the IFC model and IFC data, which can be queried through existing technologies and languages after being processed.

We consider that the classification of BIM IoT data integration methods in Table 1 requires some extension with the advent of new technologies. The openBIM methodology proposed in this paper cannot be completely classified into any of those categories, as it shares some characteristics of multiple methods. The characteristics of the openBIM approach that we propose are:

- Flexible schema: Data in the OpenBIM approach is not constraint by a classical relation data schema. A flexible data schema is proposed to facilitate data collection from diverse data sources.

- Standardised metadata: Predefined common metadata attributes to tag data from different sources homogeneously in the data platform. These agreed metadata attributes also enable dynamic data integration and multi-format conversion.

- Real-time perspective: One of the main goals is to enable rapid data transfers by limiting the size of data packages. This reduces the latency of data end-to-end and allows timely decision-making.

We have implemented this data management approach by using JSON Objects throughout the platform. JSON is a Not Only Structured Query Language (NoSQL) approach with a flexible schema. The flexibility is managed through predefined attributes to tag each data message. There is no need for a particular querying language, since JSON Objects can be serialised in plain text. This also supports rapid data transfer given that data coming from dynamic sources send small packages embedding data in individual JSON files. BIM information is extracted from the original IFC files with BIM tools APIs and integrated as required by the AM applications. Thus, it is possible to assert that our approach could be considered as a combination of all the categories in Table 1, leveraging most advantages from each one of them. Further quantitative investigation of the methodology performance is necessary, particularly when comparing it with other integration architectures.

From the application perspective, the designed IFC scheme opens the door for a diversity of AM applications. Through the definition of the IRs at the beginning of the specific application development, it is possible to integrate both real-time and static information from different systems to support conventional and dynamic decision-making in AM. Overcoming the challenge of fragmented data, the use of diverse information collected in the design, construction and, particularly, the use 
phase, together, can be beneficial for a variety of AM practices, such as commissioning and closeout, quality control and assurance, energy management, maintenance and repair, and space management [54]. Within this context, the proposed methodology will be further tested in applications requiring IFC data to be re-aggregated according to a different criteria, supporting information management and static/dynamic data integration.

\section{Conclusions}

The proposed approach has shown good applicability to existing buildings, allowing the issues arising from the lack or incompleteness of data to be addressed. Through the proposed methodology, the potential of data usually siloed in their own domain can be accessed more easily, supporting the development of AM applications for cognitive buildings. It offers an effective approach to data integration in the mid-term perspective, providing support for both the integration of static AM information and real-time IoT data. Furthermore, this paper demonstrates the potential of the openBIM approach in built AM, enabling a data-driven approach that can help to reduce the uncertainty arising from the lack of knowledge on the physical and digital assets and automating operations. In future research, its robustness should be tested in the development of additional application case studies.

Author Contributions: Conceptualization, N.M., X.X.; methodology, N.M., X.X.; software, N.M., X.X.; validation, N.M., X.X., J.M., J.B., A.K.P.; formal analysis, N.M., X.X.; investigation, N.M., X.X., J.M., J.B., A.K.P.; resources, A.K.P.; data curation, N.M., X.X., J.M.; writing-original draft preparation, N.M., X.X., J.M.; writing-review and editing, N.M., X.X., J.M., J.B., A.K.P.; visualization, N.M., X.X.; supervision, A.K.P.; project administration, A.K.P.; funding acquisition, A.K.P. All authors have read and agreed to the published version of the manuscript.

Funding: This research forms part of the Centre for Digital Built Britain's (CDBB) work at the University of Cambridge within the Construction Innovation Hub (CIH). The CIH is funded by UK Research and Innovation through the Industrial Strategy Fund.

Conflicts of Interest: The authors declare no conflict of interest.

\section{References}

1. International Organization for Standardization (ISO). ISO 55000:2014 Asset Management Overview, Principles and Terminology; ISO: Geneva, Switzerland, 2014.

2. Lu, Q.; Xie, X.; Parlikad, A.K.; Schooling, J.M.; Konstantinou, E. Moving from building information models to digital twins for operation and maintenance. Proc. Inst. Civ. Eng. Smart Infrastruct. Constr. 2020, 1-11. [CrossRef]

3. Wong, J.K.W.; Ge, J.; He, S.X. Digitisation in facilities management: A literature review and future research directions. Autom. Constr. 2018, 92, 312-326. [CrossRef]

4. International Organization for Standardization (ISO). EN ISO 19650-1:2018. Organization and Digitization of Information about Buildings and Civil Engineering Works, Including Building Information Modelling (BIM)_Information Management Using Building Information Modelling. Part 1: Concepts and Principles; ISO: Geneva, Switzerland, 2018.

5. International Organization for Standardization (ISO). EN ISO 19650-2:2018. Organization and Digitization of Information about Buildings and Civil Engineering Works, Including Building Information Modelling (BIM)_Information Management Using Building Information Modelling. Part 2: Delivery Phase of the A; ISO: Geneva, Switzerland, 2018.

6. International Organization for Standardization (ISO). EN ISO 19650-3:2020. Organization and Digitization of Information about Buildings and Civil Engineering Works, Including Building Information Modelling (BIM)_Information Management Using Building Information Modelling; ISO: Geneva, Switzerland, 2018.

7. Royal Institute of British Architects (RIBA). RIBA Plan of Work 2020 Overview; Technical Report; RIBA: London, UK, 2020. [CrossRef]

8. Patacas, J.; Dawood, N.; Kassem, M. BIM for facilities management: A framework and a common data environment using open standards. Autom. Constr. 2020, 120, 103366. [CrossRef]

9. Moretti, N.; Re Cecconi, F. A cross-domain decision support system to optimize building maintenance. Buildings 2019, 9, 161. [CrossRef] 
10. Chen, C.J.; Chen, S.Y.; Li, S.H.; Chiu, H.T. Green BIM-based building energy performance analysis. Comput. Aided Des. Appl. 2017, 14, 650-660. [CrossRef]

11. Wong, J.K.W.; Zhou, J. Enhancing environmental sustainability over building life cycles through green BIM: A review. Autom. Constr. 2015, 57, 156-165. [CrossRef]

12. Santos, R.; Costa, A.A.; Silvestre, J.D.; Pyl, L. Integration of LCA and LCC analysis within a BIM-based environment. Autom. Constr. 2019, 103, 127-149. [CrossRef]

13. Ding, L.; Drogemuller, R.; Akhurst, P.; Hough, R.; Bull, S.; Linning, C. Towards sustainable facilities management. In Technology, Design and Process Innovation in the Built Environment; Taylor \& Francis: London, UK, 2009; pp. 373-392.

14. Jourdan, M.; Meyer, F.; Bacher, J.P. Towards an integrated approach of building-data management through the convergence of Building Information Modelling and Internet of Things. J. Phys. Conf. Ser. Inst. Phys. Publ. 2019, 1343, 12135. [CrossRef]

15. Tang, S.; Shelden, D.R.; Eastman, C.M.; Pishdad-Bozorgi, P.; Gao, X. A review of building information modeling (BIM) and the internet of things (IoT) devices integration: Present status and future trends. Autom. Constr. 2019, 101, 127-139. [CrossRef]

16. Bolton, A.; Butler, L.; Dabson, I.; Enzer, M.; Evans, M.; Fenemore, T.; Harradence, F.; Keaney, E.; Kemp, A.; Luck, A.; et al. The Gemini Principles; CDBB: Cambridge, UK, 2018.

17. BuildingSMART International. Enabling an Ecosystem of Digital Twins. A buildingSMART International Positioning Paper. How to Unlock Economic, Social, Environmental and Business Value for the Built Asset Industry. Available online: https:/ /www.buildingsmart.org/wp-content/uploads/2020/05/Enabling-Di gital-Twins-Positioning-Paper-Final.pdf (accessed on 20 November 2020).

18. Lu, Q.; Parlikad, A.K.; Woodall, P.; Don Ranasinghe, G.; Xie, X.; Liang, Z.; Konstantinou, E.; Heaton, J.; Schooling, J. Developing a Digital Twin at Building and City Levels: Case Study of West Cambridge Campus. J. Manag. Eng. 2020, 36, 1-19. [CrossRef]

19. Dixit, M.K.; Venkatraj, V.; Ostadalimakhmalbaf, M.; Pariafsai, F.; Lavy, S. Integration of facility management and building information modeling (BIM): A review of key issues and challenges. Facilities 2019, 37, 455-483. [CrossRef]

20. Baldini, G.; Barboni, M.; Bono, F.; Delipetrev, B.; Duch Brown, N.; Fernandez Macias, E.; Gkoumas, K.; Joossens, E.; Kalpaka, A.; Nepelski, D.; et al. Digital Transformation in Transport, Construction, Energy, Government and Public Administration Technical Report; Publications Office of the European Union: Luxembourg, 2019. [CrossRef]

21. BuildingSMART International. openBIM. Available online: https://www.buildingsmart.org/about/openbi $\mathrm{m} /$ (accessed on 20 November 2020).

22. The British Standards Institution (BSI). Building Information Modelling (BIM). Available online: https: / / www.bsigroup.com/en-GB/Building-Information-Modelling-BIM/ (accessed on 20 November 2020).

23. Bryde, D.; Broquetas, M.; Volm, J.M. The project benefits of building information modelling (BIM). Int. J. Proj. Manag. 2013, 31, 971-980. [CrossRef]

24. Azhar, S. Building information modeling (BIM): Trends, benefits, risks, and challenges for the AEC industry. Leadersh. Manag. Eng. 2011, 11, 241-252. [CrossRef]

25. Andrade, R.O.; Yoo, S.G. A comprehensive study of the use of LoRa in the development of smart cities. Appl. Sci. (Switzerland) 2019, 9, 4753. [CrossRef]

26. Boje, C.; Guerriero, A.; Kubicki, S.; Rezgui, Y. Towards a semantic Construction Digital Twin: Directions for future research. Autom. Constr. 2020, 114, 103179. [CrossRef]

27. Alizadehsalehi, S.; Yitmen, I. The Impact of Field Data Capturing Technologies on Automated Construction Project Progress Monitoring. Procedia Eng. 2016, 161, 97-103. [CrossRef]

28. Park, C.S.; Lee, D.Y.; Kwon, O.S.; Wang, X. A framework for proactive construction defect management using BIM, augmented reality and ontology-based data collection template. Autom. Constr. 2013, 33, 61-71. [CrossRef]

29. Zekavat, P.R.; Moon, S.; Bernold, L.E. Performance of short and long range wireless communication technologies in construction. Autom. Constr. 2014, 47, 50-61. [CrossRef]

30. Dave, B.; Kubler, S.; Främling, K.; Koskela, L. Opportunities for enhanced lean construction management using Internet of Things standards. Autom. Constr. 2016, 61, 86-97. [CrossRef] 
31. Sacks, R.; Perlman, A.; Barak, R. Construction safety training using immersive virtual reality. Constr. Manag. Econ. 2013, 31, 1005-1017. [CrossRef]

32. Cheung, W.F.; Lin, T.H.; Lin, Y.C. A Real-Time Construction Safety Monitoring System for Hazardous Gas Integrating Wireless Sensor Network and Building Information Modeling Technologies. Sensors 2018, $18,436$. [CrossRef]

33. Chang, K.M.; Dzeng, R.J.; Wu, Y.J. An automated IoT visualization BIM platform for decision support in facilities management. Appl. Sci. (Switzerland) 2018, 8, 1086. [CrossRef]

34. Herbers, P.; König, M. Indoor localization for augmented reality devices using BIM, point clouds, and template matching. Appl. Sci. (Switzerland) 2019, 9, 4260. [CrossRef]

35. Lu, Q.; Xie, X.; Parlikad, A.K.; Schooling, J.M. Digital twin-enabled anomaly detection for built asset monitoring in operation and maintenance. Autom. Constr. 2020, 118, 103277. doi:10.1016/j.autcon.2020.103277. [CrossRef]

36. Moretti, N.; Blanco Cadena, J.D.; Mannino, A.; Poli, T.; Re Cecconi, F. Maintenance service optimization in smart buildings through ultrasonic sensors network. Intell. Build. Int. 2020. doi:10.1080/17508975.2020.1765723. [CrossRef]

37. Rinaldi, S.; Bellagente, P.; Camillo Ciribini, A.L.; Chiara Tagliabue, L.; Poli, T.; Giovanni Mainini, A.; Speroni, A.; Blanco Cadena, J.D.; Lupica Spagnolo, S. A cognitive-driven building renovation for improving energy effciency: The experience of the elisir project. Electronics (Switzerland) 2020, 9, 666. [CrossRef]

38. Marzouk, M.; Abdelaty, A. Monitoring thermal comfort in subways using building information modeling. Energy Build. 2014, 84, 252-257. [CrossRef]

39. Woo, J.H.; Peterson, M.A.; Gleason, B. Developing a Virtual Campus Model in an Interactive Game-Engine Environment for Building Energy Benchmarking. J. Comput. Civ. Eng. 2016, 30, C4016005. [CrossRef]

40. Solihin, W.; Eastman, C.; Lee, Y.C.; Yang, D.H. A simplified relational database schema for transformation of BIM data into a query-efficient and spatially enabled database. Autom. Constr. 2017, 84, 367-383. [CrossRef]

41. Khalili, A.; Chua, D.K.H. IFC-Based Graph Data Model for Topological Queries on Building Elements. J. Comput. Civ. Eng. 2015, 29, 04014046. [CrossRef]

42. Mazairac, W.; Beetz, J. BIMQL-An open query language for building information models. Adv. Eng. Inform. 2013, 27, 444-456. [CrossRef]

43. Alves, M.; Carreira, P.; Costa, A.A. BIMSL: A generic approach to the integration of building information models with real-time sensor data. Autom. Constr. 2017, 84, 304-314. [CrossRef]

44. Dibley, M.; Li, H.; Rezgui, Y.; Miles, J. An ontology framework for intelligent sensor-based building monitoring. Autom. Constr. 2012, 28,1-14. [CrossRef]

45. Curry, E.; O’Donnell, J.; Corry, E.; Hasan, S.; Keane, M.; O'Riain, S. Linking building data in the cloud: Integrating cross-domain building data using linked data. Adv. Eng. Inform. 2013, 27, 206-219. [CrossRef]

46. Hu, S.; Corry, E.; Curry, E.; Turner, W.J.; O’Donnell, J. Building performance optimisation: A hybrid architecture for the integration of contextual information and time-series data. Autom. Constr. 2016, 70, 51-61. [CrossRef]

47. McGlinn, K.; Yuce, B.; Wicaksono, H.; Howell, S.; Rezgui, Y. Usability evaluation of a web-based tool for supporting holistic building energy management. Autom. Constr. 2017, 84, 154-165. [CrossRef]

48. International Organization for Standardization (ISO). ISO 16739-1:2018-Industry Foundation Classes (IFC) for Data Sharing in the Construction and Facility Management Industries-Part 1: Data Schema; ISO: Geneva, Switzerland, 2018.

49. International Organization for Standardization (ISO). BS EN ISO 12006-3:2016. Building Construction-Organization of Information about Construction Works-Part 3: Framework for Object-Oriented Information; ISO: Geneva, Switzerland, 2016.

50. Maltese, S.; Branca, G.; Re Cecconi, F.; Moretti, N. Ifc-based Maintenance Budget Allocation. In_Bo 2018, 9, 44-51. [CrossRef]

51. Dong, B.; O’Neill, Z.; Li, Z. A BIM-enabled information infrastructure for building energy Fault Detection and Diagnostics. Autom. Constr. 2014, 44, 197-211.

52. International Organization for Standardization (ISO). BS EN ISO 29481-1:2017 Building Information Models_Information Delivery Manual. Part 1: Methodology and Format; ISO: Geneva, Switzerland, 2017.

53. International Organization for Standardization (ISO). ISO/PAS 16739:2005-Industry Foundation Classes, Release 2x, Platform Specification (IFC2x Platform); ISO: Geneva, Switzerland, 2005. 
54. Becerik-Gerber, B.; Jazizadeh, F.; Li, N.; Calis, G. Application areas and data requirements for BIM-enabled facilities management. J. Constr. Eng. Manag. 2012, 138, 431-442.

55. BuildingSMART International. Technical Roadmap buildingSMART: Getting Ready for the Future. Available online: https:/ /www.buildingsmart.org/wp-content/uploads/2020/09/20200430_buildingSM ART_Technical_Roadmap.pdf (accessed on 20 November 2020).

Publisher's Note: MDPI stays neutral with regard to jurisdictional claims in published maps and institutional affiliations.

(C) 2020 by the authors. Licensee MDPI, Basel, Switzerland. This article is an open access article distributed under the terms and conditions of the Creative Commons Attribution (CC BY) license (http:/ / creativecommons.org/licenses/by/4.0/). 